\title{
Methods of Financing Waqf Development in Singapore
}

Ashraf Jomah Mohammed Nasar*

International Islamic University Malaysia (IIUM), Malaysia.

Email: $\underline{\text { Ash.jsk845@gmail.com }}$

Abdulmajid Obaid Hasan Saleh

International Islamic University Malaysia (IIUM), Malaysia.

Email: alamri@iium.my

Falah M F SM Alhajri

Kuwait University, Kuwait.

Email: falahalhajri2020@gmail.com

\section{El Amrani Taoufiq}

The Regional Academy of Education and Training in Casablanca, Morocco

Email: elamranitaoufiq@yahoo.fr

Received September, 2019; Accepted December, 2019

\begin{abstract}
The Waqf sector in the Muslim world is in general neglected. It lacks tactics and strategies due to various conflicting and overlapping factors. Remarkably, Singapore Waqf is a pioneer and successful endowment project in the Muslim world on organizational and investment scales. The sector has impressively expanded and embraced effective methods and advanced techniques. The study addresses Singapore's experience by pinpointing the diversity of its Waqf funds: funds for mosques, funds for the disabled, memorization of the Quran, funds for education and for scientific and innovative research. Unlike the Waqf of immovable assets, the monetary Waqf has gained popularity in Singapore. It has contributed to social security and welfare through its ultimate and legitimate goal to serve the public interests. Its role consists of channeling social savings and turning them into social capital. The Waqf administration in Singapore has used Sukuk to develop some of its endowments (Waqfs). Therefore, the research aims to analyze this new funding technique and weigh its impact on funding important projects such as: The Beach Road 1- construction project and the Street Bencoolen-Waqf development and refurbishment project. The study relies on a case study and uses a descriptive-analytical approach.
\end{abstract}

Keywords: Waqf in Singapore; Cash Waqf; Finance.

Type: Research paper

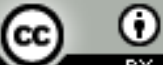

This work is licensed under a Creative Commons Attribution 4.0 International License.

DOI: 10.51325/ijbeg.v3i1.28

أساليب تمويل تطوير الأوقاف في سنغافورة ملخص البحث :

\footnotetext{
يعاني قطاع الوقف في العالم العربي والإسلامي بشكل عام حالة من التسيب والإهمال، وفقدان للحيلة في الاستفادة منه، نتيجة عوامل متراكمة ومتداخلة، الأمر الذي يستدعي البحث عن تجارب ناجحة يمكن الاستفادة منها واستتساخها، وتأتي تجربة سنغافورة في الوقف رائدة

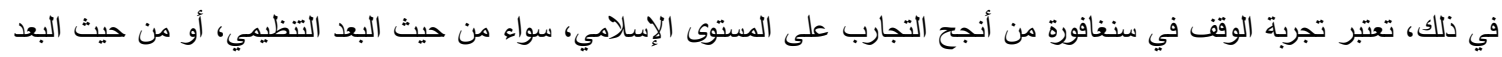
الاستثاري، وقد شهد قطاع الوقف تطورا ملحوظا حيث اكتثفت طرق وأساليب حديث ناجعة، تهدف الدراسة للكثف عن واقع هذه التجربة التهنية صناديق الوقف للمساجد، صناديق المعاقين، تحفيظ القرآن، وكذلك التعليم والبحث العلمي والابتكار وغيرها، واكتسب الوقف النقدي شعبية

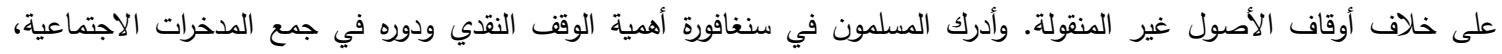

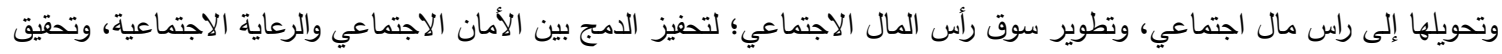




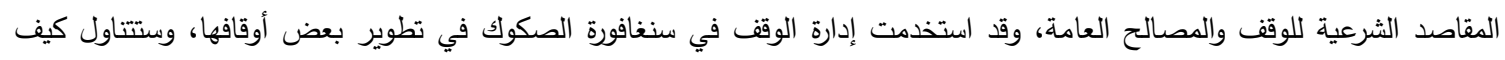

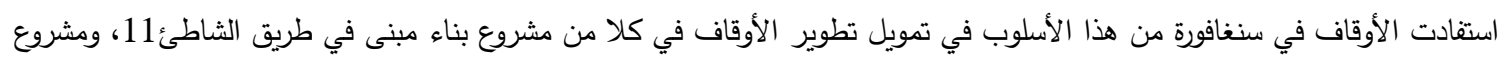

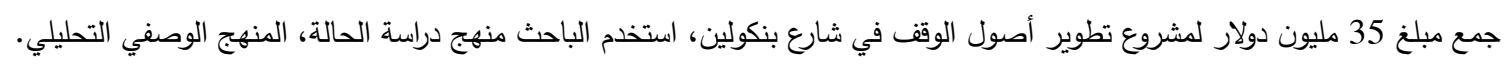
الكلمات المفتاحية: الوقف في سنغافورة، الوقف النقدي، التمويل.

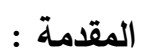

يرجع تاريخ الوقف في جزيرة سنغافورة إلى تاريخ دخول الإسلام إلى الجزيرة، بما فيها المناطق التي تطلق عليها

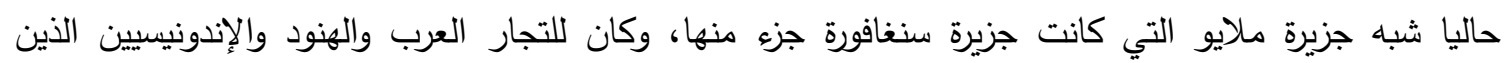

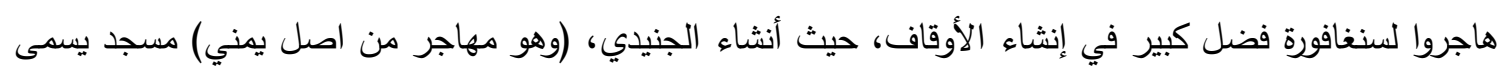

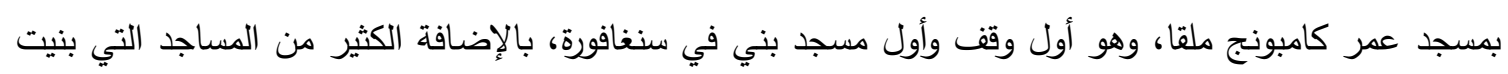

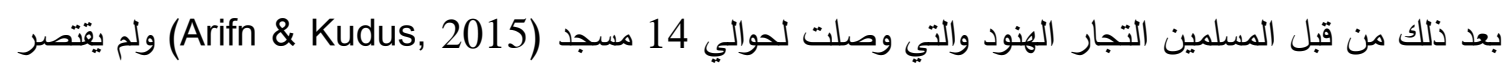
الأمر على أنثاء المساجد بل قاموا بشراء عقارات وخصصت للإيجار والعائد من الإيجار خصص الفص للصيانة الأوقاف

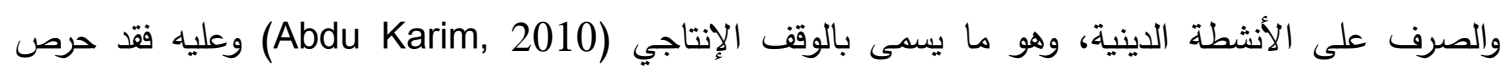

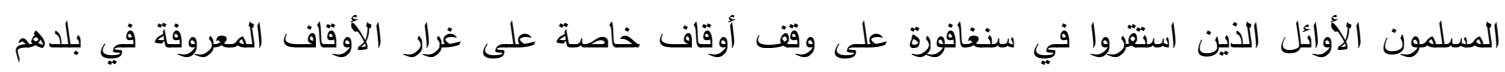

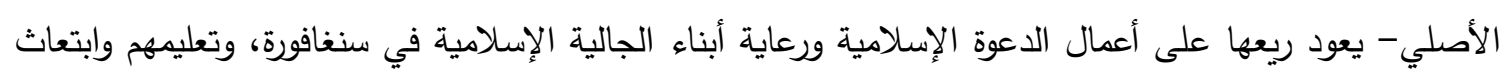
البعض منهم إلى الدول الإسلامية، خاصة إلى حضرموت واليمن موطن غالبية المهاجرين الأوائل وذلك لكي يتعلموا

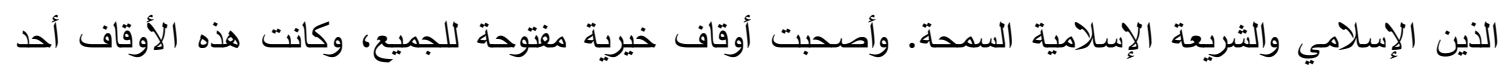

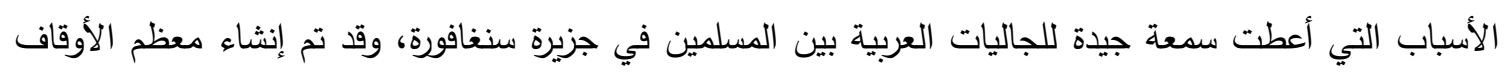

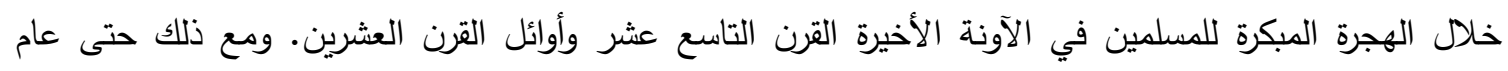
2010م، لم يكن هناك إبداعات جديدة في إنثاء الوقف ربما يرجع إلى الأسباب التالية: 1- عدم وجود معلومات حول إنثاء الوقف والتي تودي إلى التوسع في إنشاءه.

2- ارتفاع أسعار العقارات بما يتجاوز إمكانيات الكثير من المسلمين السنغافوريين.

3- هناك العديد من أشكال التبرعات الأخرى والتي تستهدف المسلمين في سنغافورة مثل المدارس التهات

$$
\text { والمساجد مع الترويج القليل لأموال المؤسسة الوقفية. }
$$

4-كل وقف ينسب إلى Muis، هي أوقاف أولئك الذين لا يرتاحون لإدارة أصول أموالهم من قبل هيئة حكومية، أو الذين يفضلون إدارة أوقافهم الخاص بهم دون أي تدخل من السلطات من خلافل الأمناء المعينين ذاتياً وقد يمتتعون عن أنثاء الأوقاف. (Ibrahim \& Datuk, 1965).

مشكلة البحث:

يهدف البحث لاكتثاف وإبراز تجربة جديدة ناجعة آتت ثمارها، حرية بالدراسة والملاحظة، والاستساخ للاستفادة

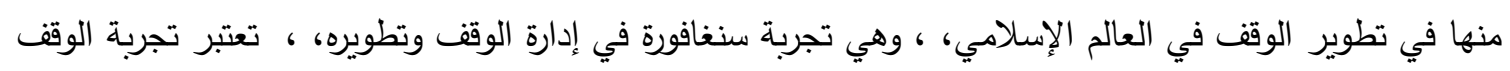

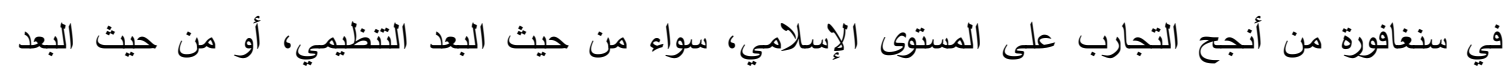

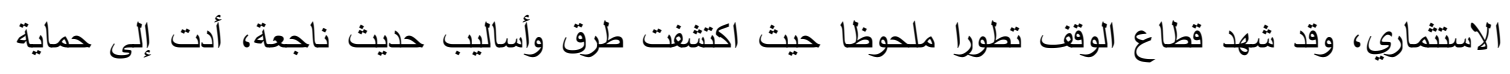
الوقف وتطوره بطريقة تتواكب مع متطلبات العصر وعصر التتمية، فهناك الوقف النقدي والذي تمثلت في الآتي : صناديق الوقف للمساجد، صناديق المعاقين، تحفيظ القرآن، وكذلك التعليم والبحث العلدي والابتكار وغيرها، 
واكتسب الوقف النقدي شعبية على خلاف أوقاف الأصول غير المنقولة. وأدرك المسلمون في سنغافورة أهمية الوقف

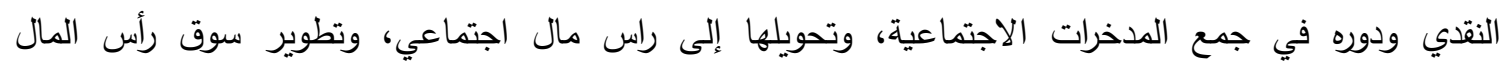

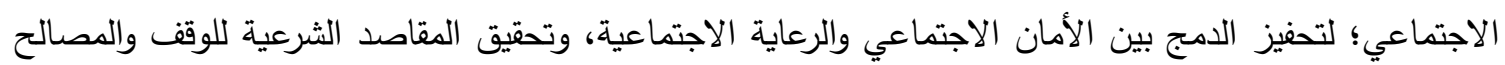

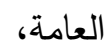
وقد استخدمت إدارة الوقف في سنغافورة الصكوك في تطوير بعض أوقافها، وستتاول كيف استفادت الأوقاف في

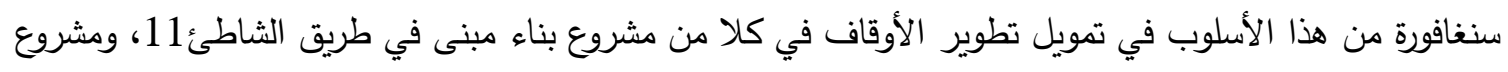

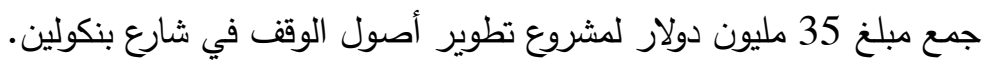

الأول: الإطار النظري للدراسة التعريف بواقع الوقف في سنغافورة وبيان خصوصيته. في قانون إدارة المسلمين (AMLA)، يتم تعريف الوقف على النحو التالي:

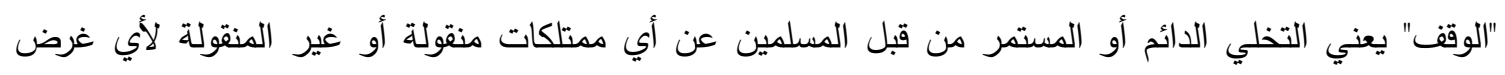
ديني أو خيري1. ويقسم قانون AMLA الوقف إلى نوعين منفصلين من الأوقاف، النوع الأول هو الوقف العام أو الوقف

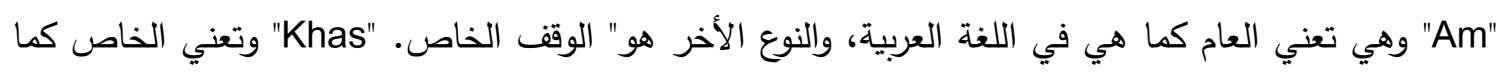

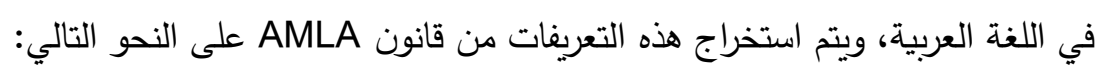

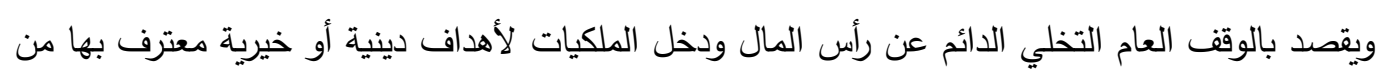
قبل المسلمين والقانون.

"الوقف الخاص" يعني التخلي الأبدي عن راس المال أو الممتلكات الخاصة لأغراض دينية أو خيرية

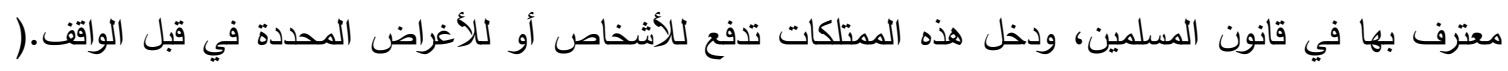
. (AMLA

(MUIS] Majlis Ugama Islam Singapore) كجلس الإسلامي السنغافوري (AMLA) قبل صدور قانون (AMLA) كانت جميع الأوقاف الموجودة في سنغافورة تدار من قبل الدجلس الداعم للمسلمين والهندوس الذي صدر في 8 سبتمبر 1905م، (Abdu Karim, 2010) وفي عام 1968 أنُشأ قانون إدارة شؤون

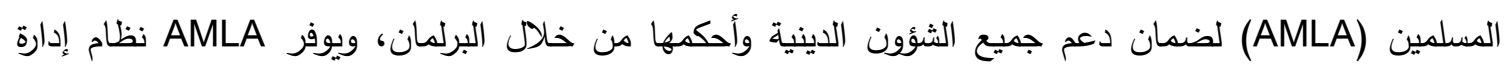
مركزي يغطي جميع جوانب حياة المسلمين في سنغافورة، وبموجب هذا القانون تم تثكيل المجلس الإسلامي الديني في سنغافورة (MUIS)، وهو يتصرف كهيئة قانونية تشرف على شؤون المسلمين في سنغافورة، ويختص بإدارة

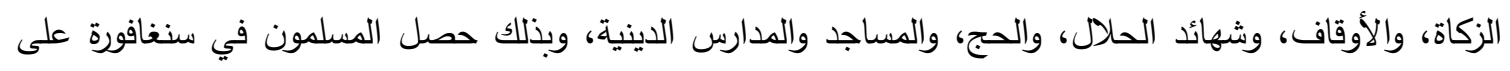
ميزة خاصة، لأن أيًا من أصحاب الأديان الأخرى لم يحصل على ولى هذا الحق، والمجلس تحت إشراف وزارة تتمية

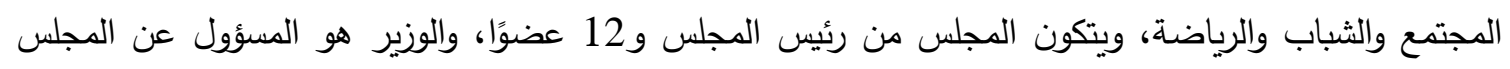

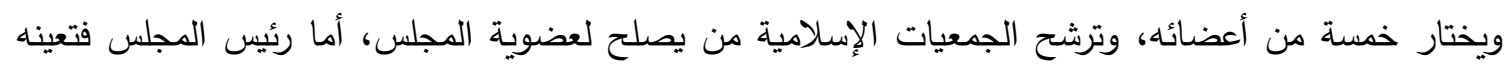
الحكومة وكذلك الأمين العام للمجلس، والمفتي يعينه رئيس الدولة وهو عضو في المجلس ومنصبيه ثابت الديت لا يتغير

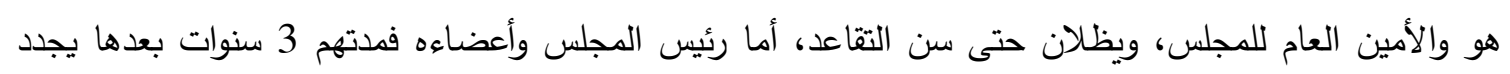

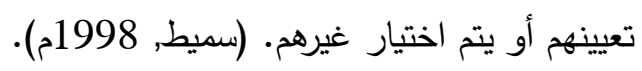


وفيما يتعلق بدور المجلس الإسلامي فهو ممثل المسلمين أمام الحكومة، وقد أُعطي هذا المجلس الإسلامي صلاحيات واسعة إدارية وتتفيذية في الإشراف على المساجد والمدارس الإسلامية.

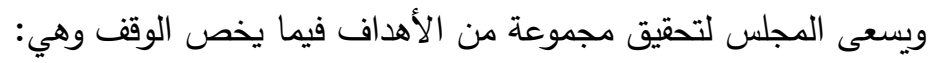

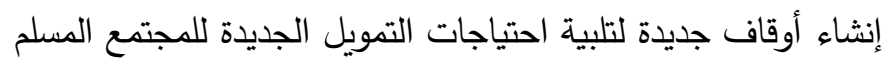
• الاستمرار في إعادة تطوير جميع ممتلكات الأوقاف والمحافظة عليها.

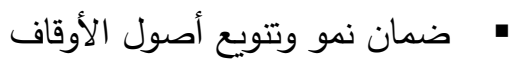

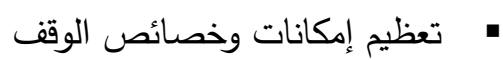

$$
\begin{aligned}
& \text { • إدارة صندوق الأوقاف بكفاءة وفعالية } \\
& \text { إثبات أن الوقف هو صيغة نموذجية للإنفاق الخيري } \\
& \text { توجيه العائدات الوقفية نحو تتمية المجتمع.2 }
\end{aligned}
$$

\section{الهيكل القانوني للوقف في سنغافورة}

قبل ظهور قانون إدارة القانون الإسلامي في 1 يوليو 1968، تم تتظيم كل التبرعات والجمعيات الخيرية بموجب

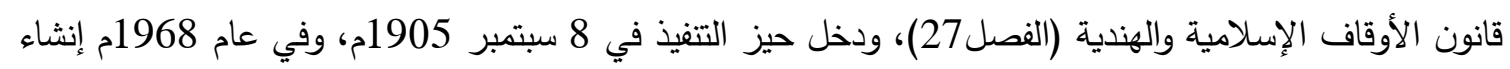

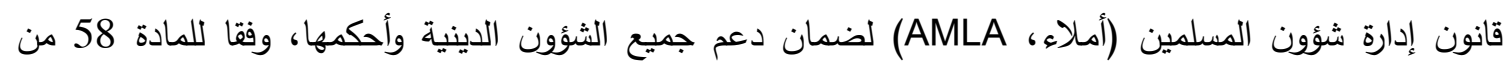

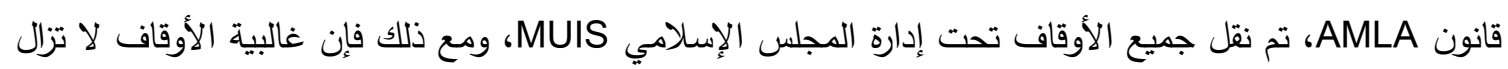

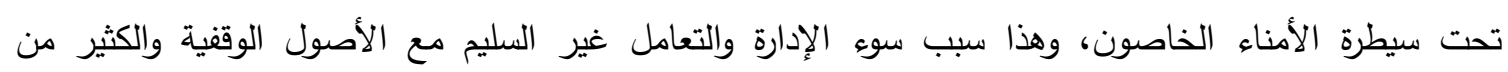

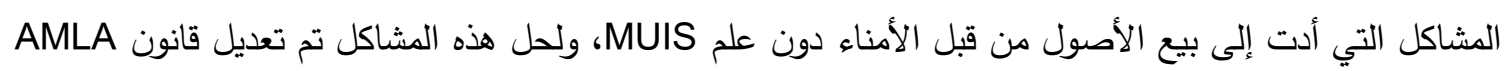
في عام 1995م ليصبح تسجيل جميع مؤسسات الوقف إلزاميًا تحت مظلة المجلس، وحصلت تعديلات مختلفة التئة لتطوير نظام إدارة الوقف وتقويته(Abdu Karim, 2010) ويتضمن قانون AMLA العديد من الأحكام القانونية الكتعلقة بإدارة الوقف، وتتضمن هذه الأحكام استحقاق الوقف، وتسجيل الوقف، الاعتماد المالي الأوقاف كما في

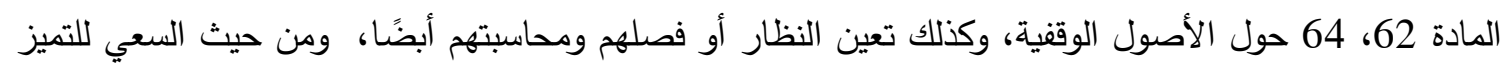

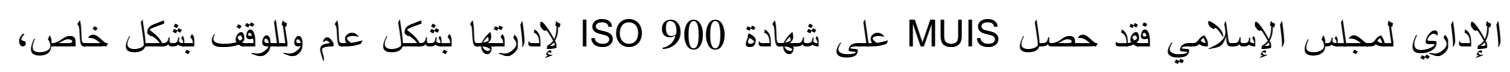
ويسعى المجلس باستمرارية هذا النظام الإداري المتميز، وحقق المجلس أيضا علامة الجودة من الالتزام بالوفاء

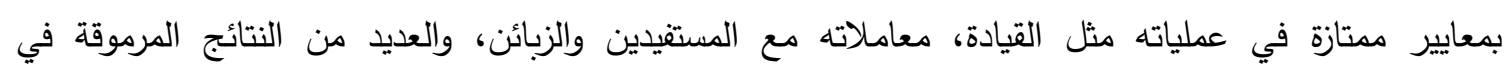

خصائص الوقف في سنغافورة: وقد تم اختيار تجربة سنغافورة في تطوير وإدارة قطاع الأوقاف لعدة أسباب منها: -

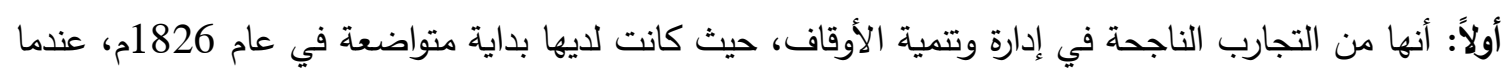
كان أول أصول الأوقاف مسجد عمر في شارع كامبونج ميلاكا، واليوم، تقدر القيمة الإجمالية لأصول الوقف في

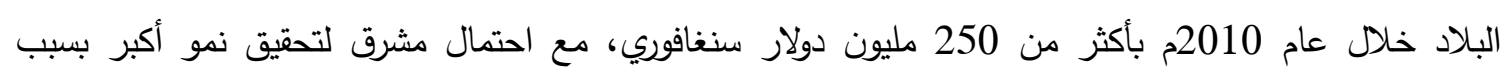

الكفاءة إدارة الأصول. (Abdu Karim, 2010)

https://www.muis.gov.sg الموقع الرسمي للمجلس الإسلامي سنغافورة 3


ثانياً: قدمت سنغافورة نموذج مميز في إدارة الأوقاف من خلال الامج ما بين العامل الخيري والعمل التجاري، من

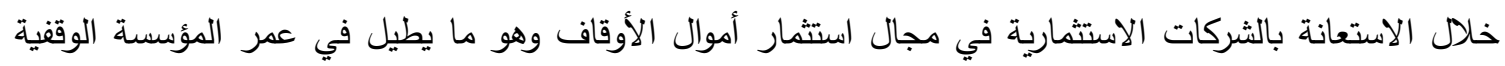

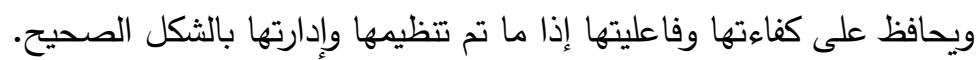
ثالثاً: يبدو أن نهج سنغافورة في تطوير التنمية هو نهج متوازن، حيث اعتددت على تطوير الأصول الوقفية العقارية إلى جانب مواكبة النطور في الأوقاف من خلا الأوقاف النقدية، فقد تم تطوير عدد كبير من العقارات وأصبحت ذات عائد كبير وحققت فوائد اجتماعية كثيرة للمجتمع السنغافوري، وكذلك وضعت خلاوفة خطة للوقف النقدي يستفيد منه شريحة كبيرة من المجتمع ويساهم فيه مختلف شرائح المجتمع باختلاف مستويات دخولهم.

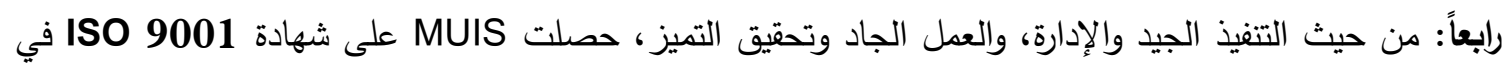
إدارة الوقف، كذلك حصل الدجلس أيضًا على لقب السنغافوريين المؤهلين، الذين لديهم هدف الالتزام التنظيمي في

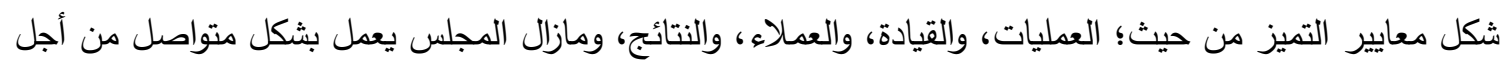
استمرار هذا التميز في نظام الإدارة. الفرع الثاني: أساليب تمويل تطوير الأوقاف في سنغافورة تمويل الوقف هو التفكير بأسلوب علمي للحصول على رؤوس أموال لتغطية حاجات الوقف ولرعايته وتتميته ولزيادة

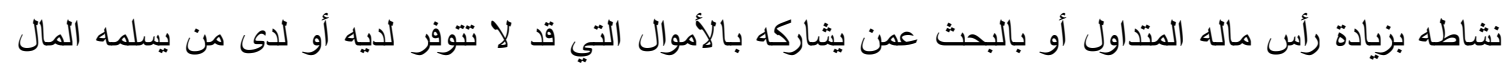

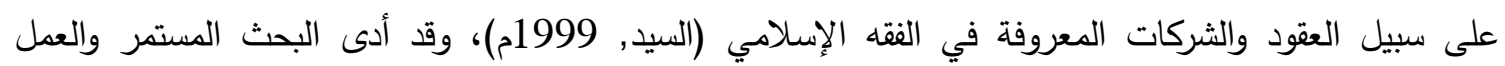
الريادي لتطوير وإحياء الأصول الوقفية إلى ابتكار أساليب تمويل مختلفة لتطوير عقارات الوقف في جميع أنحاء

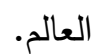

اعتمد المجلس الإسلامي بسنغافورة على أسلوب التمويل الداخلي والخارجي (المشروعات المشتركة)

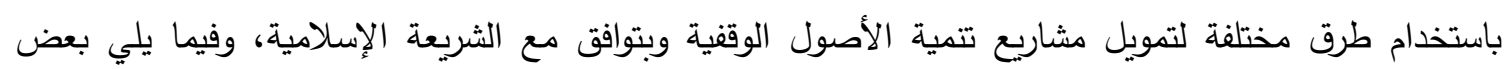
الأدوات المستخدمة لتمويل تطوير الوقف فبي سنغافورة: 1- استخدام التمويل القائم على حقوق الملكية - المشاركة (المشروع المشترك) والمضاربة (تقاسم الأرباح) 2- استخدام التمويل المستتد إلى الديون - إجارة، استصناع، صكوك التهويل

3- استخدام التمويل الداخلي مثل قرض من بيت مال، أو حكومة، أو باستخدام أموال الوقف الخاصة.

قرض حسن، استبدال (Abdu, 2010).

أولًا - التمويل القائم على حقوق الملكية

أ أ- المشاركة (مشروع مشترك)

يعتبر العديد من العلماء أن المشاركة هي الأكثر أصالة في العقد الإسلامي، وكان يمارس في شبه الجزيرة العربية

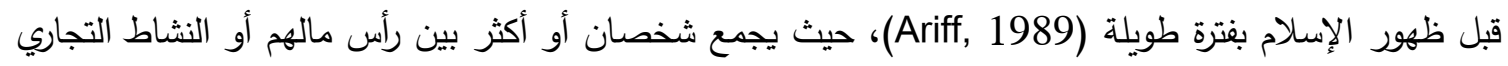
معا، وأية خسائر يتم وفقا لمساهمة رأس المال. التمويل القائم على حقوق الملكية، وهو الأسلوب الرائد لتمويل الأصول الوقفي للمجلس الديني الإسلامي في

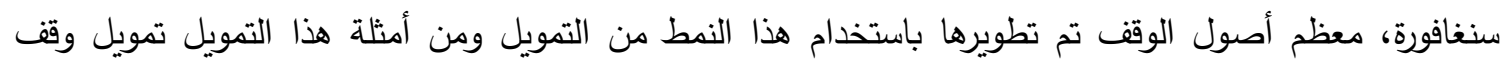
قاسم، والذي من خلاله تم الجمع بين مفهوم المشاركة في تطوير العقارات مع مفهوم الإيجار الطويل (الحكر) في لطي تطوير وقف قاسم، وفيما يلي شرح هذا النمط من التمويل. 
العقار: أنشاء وقف مسجد قاسم في عام 1921م كان الوقف عبارة عن قطعة أرض للمسجد، والباقي مباني

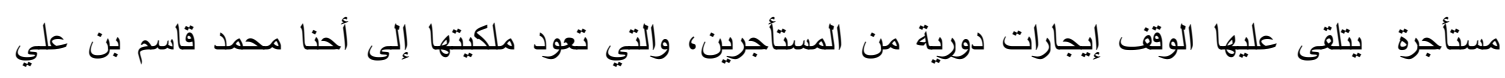
محمد، المعروف بوقف قاسم، حيث كان المسجد في حالة متداعية ويحتاج إلى إعادة بناء كبيرة لخدمة المجتمع لئك

المسلم عالي الكثافة في تلك المنطقة. التطوير: تتمثل عملية التطوير في إقامة مبنى جديد للمسجد ومجمع تجاري و40 وحدة سكنية، وقُدرت كلفة المسجد الجديد بمبلغ 5 ملايين دولار سنغافوري، وكذلك 10 مليون دولار أخرى تحتاجها المحلات من أجل توفير دخل

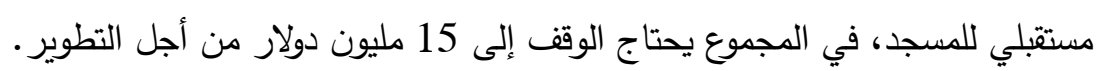

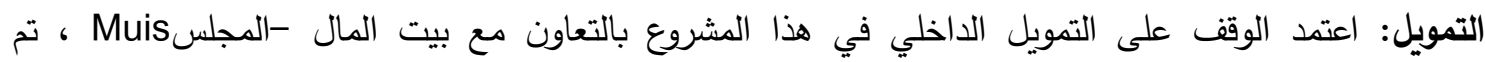

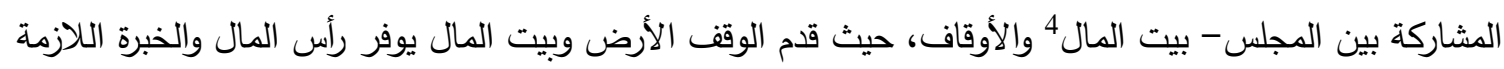
لتطوير، ولكي يتمكن بيت المال من جني رأس المال الذي قدمه، ومن أجل أن يتمكن الوقف من سداد المبلغ

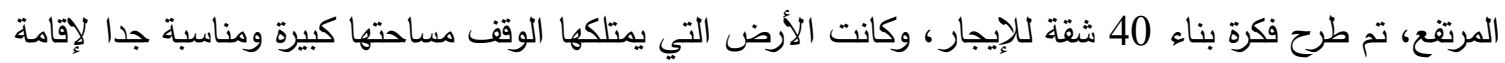
المشروع.(Abdu Karim, 2010). كيفية عمل هذا النموذج : المرحلة الأولى كانت بداية المشروع بتنفيذ الصفة التجارية إقامة 40 وحدة من الثقق المكونة من طابقين بكلفة ما مجموعه 10 ملايين دولار، والذي استغرق عامين كاملين، سبقتهما فترة طويلة من التفاوض على إخلاء جميع المحلات التجارية القديمة من المستأجرين مقابل تعويض مالي، تم تسويق العقار وتم

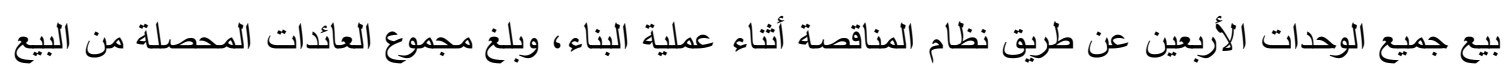

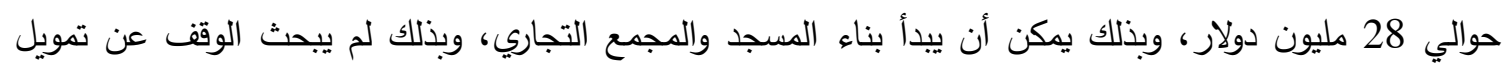

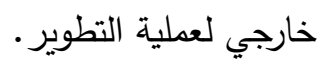
وكان صافي الربح من التطوير حوالي 15 مليون دولار، وهو ما يكفي بالضبط لتمويل المرحلة الثانية من التطوير

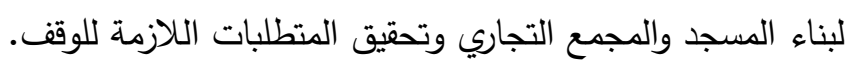
هيكل المشاركة لتمويل التطوير في المثال أعلاه، جاء الوقف وبيت المال معاً شركاء في عملية تطوير المنطقة، قدم بيت المال رأس المال بقيمة 10 ملايين دولار، وقدم الوقف الخبرة الإدارية والأرض.

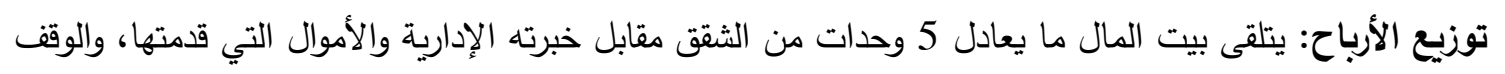

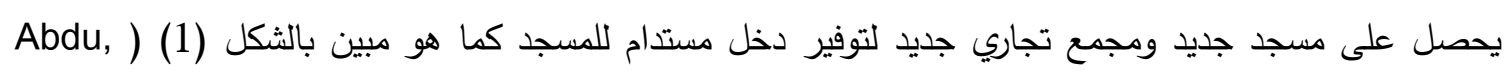
.(2010

4 بيت المال هو صندوق هبات عام يديره بجلس أوغاما إسلام سنغافورا. تم إعداد الصندوق كصندوق الأغراض العامة للجالية المسلمة بشكل عام. انظر تقرير مويس السنوي عن الأنشطة المالية وتقرير بيت المال. 


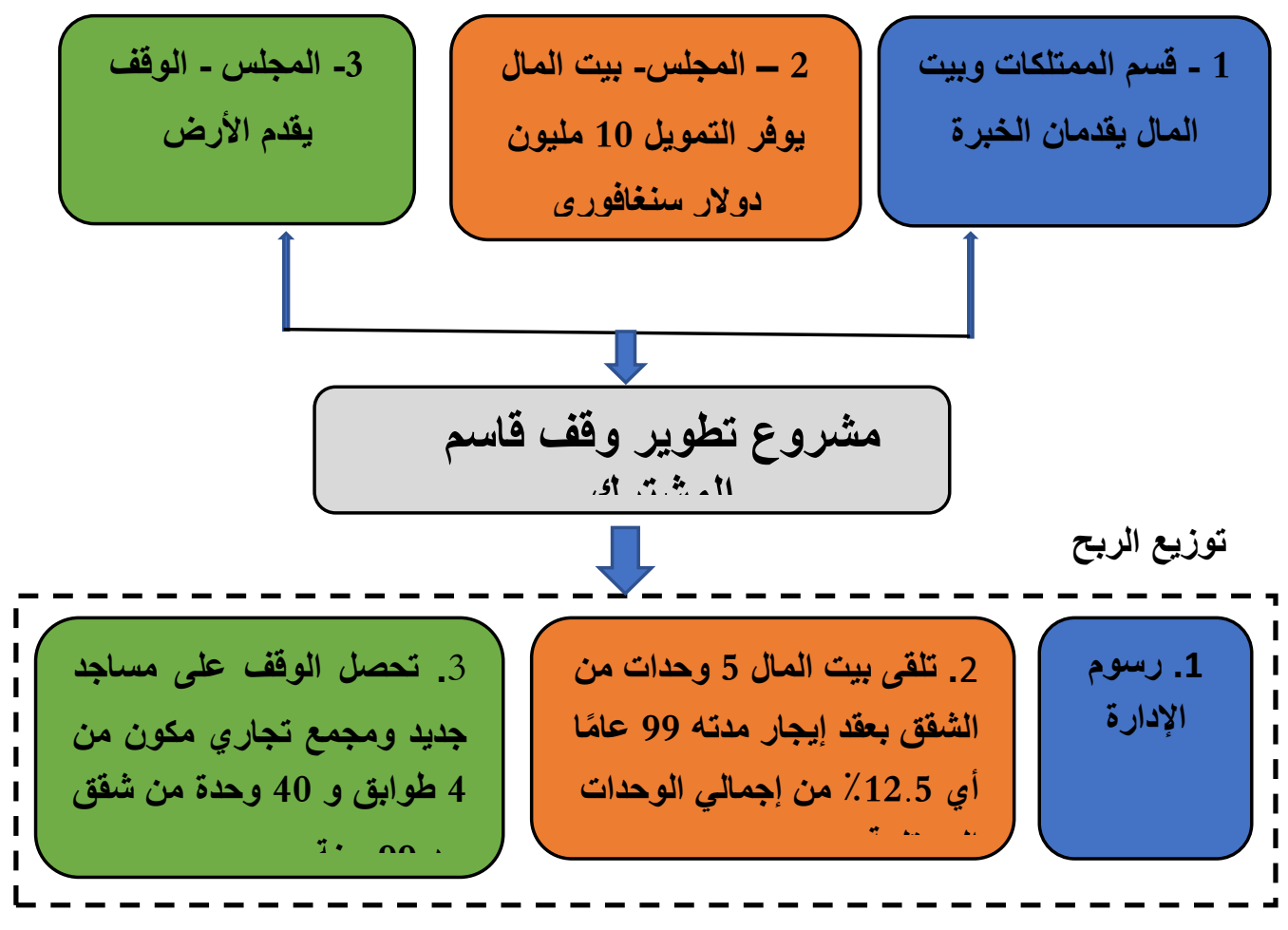

الثكل 1: - هيكل المشاركة في تمويل وقف قاسم

ب - ميكل المضاربة

تقوم فكرة المضاربة على قبول ناظر الوقف الأموال النقدية بصفته مضاربا، ويصدر فيها وثائق متساوية القيمة، ويستعمل الناظر هذه الأموال في تتمية أموال الوقف، ويقوم الناظر بحساب الربح والخسارة حسب الاتفاق (قحف,

وقد استخدمت المضاربة في تتمية وتمويل العديد من الأوقاف، وكمثال على هيكل المضاربة حالة

الأصول الوقفية في شارع ديكسون في سنغافورة.

تمويل وقف ديكسون

تم تمويل هذا الوقف بأسلوب المضاربة، حيث يقوم المستأجر بتوفير رأس المال (صاحب المال)، ويوفر المضارب

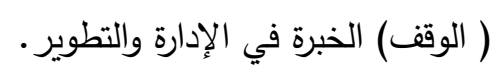

في هذا المشروع قدم المستأجر تكلفة تجديد العقارات الوقفية المتهالكة بمبلغ

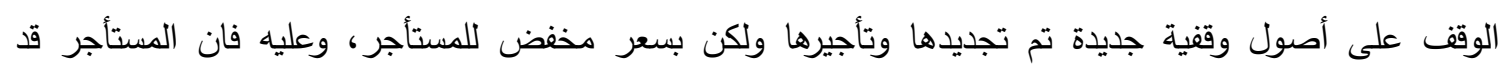
تحصل على فترة تأجير لمدة 12 سنة بسعر مخفض، وهذا أفضل من ترك الممتلكات في حالة متداعية وعدم القدرة على كسب أي إيجار، وبهذه الطريقة كان المستأجر قد احتاط من ارتفاع معدل الإيجار ، وقام بتأمين عقد الإيجار

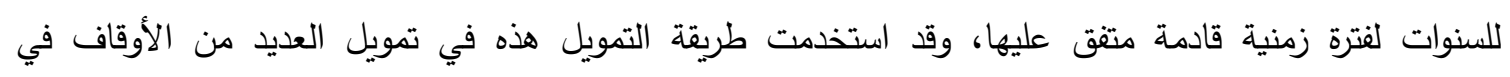
سنغافورة، للابتعاد عن الحاجة إلى الاقتراض أو التمويل عالي التكاليف (Abdu Karim, 2010). 
ثانيًا- التمويل المستند إلى الديون (الصكوك) أحد التطورات في الصناعة المالية الإسلامية هو طرح الصكوك، والصكوك هي مواصفات جديدة للديون عند

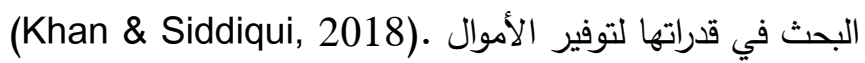
تستخدم الصكوك لجمع الأموال لتمويل المشاريع، وهي الآن تكتسب شعبية مع الحكومات التي تصدر

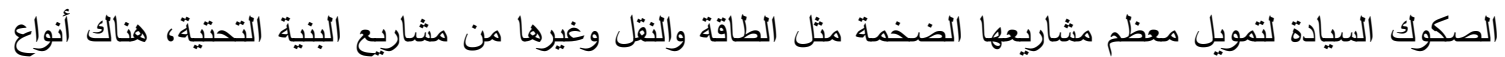
عديدة من الصكوك مثل المشاركة، الإجارة، المضاربة، المرابحة، الاستصناع، السلم، الأنواع الأكثر شعبية من من منئه

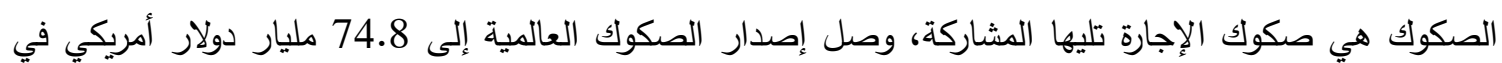

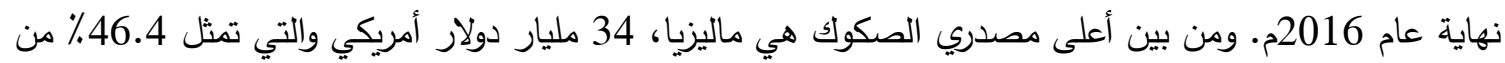
سوق الصكوك العالمية (Khouildi \& Kassim, 2018). وفي مجال الوقف، مع وجود العديد من أصول الوقف في شكل ممتلكات، يمكن للصكوك أن تكون واحدة

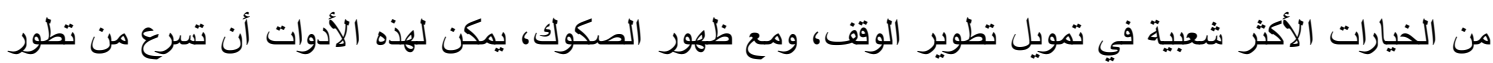
الوقف، وهو ما تحتاجه العديد من مؤسسات الأوقاف. وفي عام 2015م أصدرت خزانة ناشيونال الماليزية صكوكا أطلق عليها صكوك "إحسان،، وهي عبارة عن صكوك استثمارية ذات مسؤولية اجتماعية، الهدف من إصدارها تمويل مدارس وقفية، من خلال سوق رأس المال كتجربة هي الأولى من نوعها (Ibrahim \& Datuk). ففي حين أن الأساليب التقليدية في الأيام القديمة تستخدم أدوات الحكر والإجارة إلا أن ظهور الصكوك أدي إلى تسريع تطوير الوقف، حيث أن هناك حاجة ماسة في العديد من مؤسسات الأوقاف لتطبيق هيكل الصكوك لتطوير أوقافها.

وقد استخدمت إدارة الوقف في سنغافوة الصكوك في تطوير بعض أوقافها، وستتناول كيف استفادت الأوقاف في سنغافورة من هذا الأسلوب في تمويل تطوير الأوقاف في كلا من مشروع بناء مبنى في طريق لئي الشاطئ11، ومشروع جمع مبلغ 35 مليون دولار لمشروع تطوير أصول الوقف في شارع بنكولين.

أ - مشروع تمويل تطوير مسجد بنكولين (صكوك المشاركة) تأسيس هذا المسجد 1845م، بنسخة دائمة بناها تاجر عربي، يدعى عمر بن الجنيد، في عام 2001م، بـوئ بسبب إعادة تطوير المنطقة، تم هدمه ودمجه المسجد في مجمع سكني متعدد الاستخدامات وافتتح في عام 2004م5 كأن وهو تحت وصاية MUIS. تصودة ومن أجل تمويل هذا التطوير، اقترح المجلس حل مبتكر من خلال صكوك المشاركة، وتفاصيل هذا

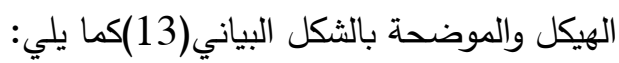

الجزء الأول من العقد - عقد المشروع المشترك / المشاركة عقد المشروع المشترك بين الأوقاف وبيت المال وشركة Wares (شركة تابعة MUIS)، تتعامل مع المجلس في تتمية العقارات الوقفية) دخلت هذه الشركة في عقد بناء مختلط لتطوير في شارع Bencoolen، ويساهم الوقف وبن

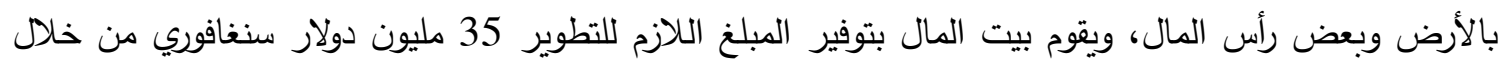
المستثرين، وشركة Wares توفر مبلغ أسمي وكذلك خبرتها الاستثمارية (Abdu Karim, 2010). 


$$
\text { الجزء الثاني من العقد - عقد الإجارة }
$$

من أجل توفير عائد للمستثرين، تم إبرام عقد التأجير بين شركة الأغراض الخاصة (تسمى هنا SPV) لإبرام عقد

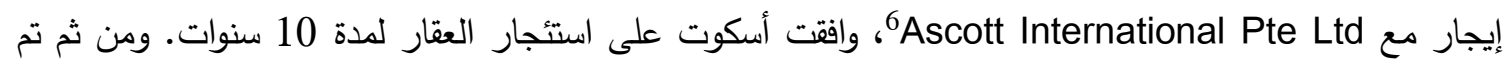
تأمين تدفق مستمر للدخل للوقف، ويمكن من خلا ذلك تقديم العائد للمستثرين، على الرغم من إصدار السندات لمدة 5 سنوات، تم توقيع عقد الإيجار لمدة 10 سنوات، وذلك لكي لا يكون هناك أي عوائق لأن هناك لأكن خيارًا للتجديد السندات بعد 5 سنوات (Abdu Karim, 2010).

توزيع الربح بناءً على اتفاق المشاركة أعلاه يتم تقسيم الربح وفقًا لذلك نسبة رأس المال المستثر كما موضح بالثكل البياني (14)، سوف يكسب المستثمرين من خلال بيت المال على تيار مستمر من الدخل على أساس إيرادات الإيجار

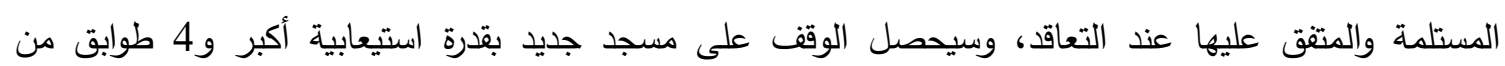
العقارات التجارية لتوفير دخل للمسجد لتشغيله والحفاظ عليه، بما أن بيت المال تحمل معظم المخاطر للقيام بتوفير

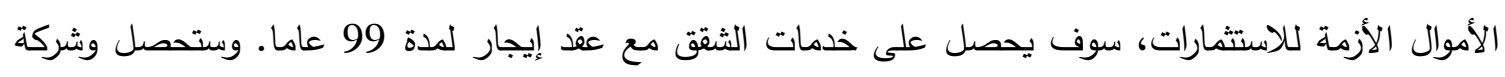

على عائد استثماري اسمي ورسوم مهنية لإدارة الاستثمار والتطوير (Kamsani \& Leung, 2005). خصائص هذا النموذج سيحصل المساجد على دخل للحفاظ عليه وتثغيله. وبما أن بيت المال تحمل

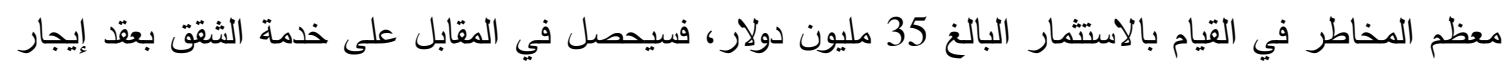

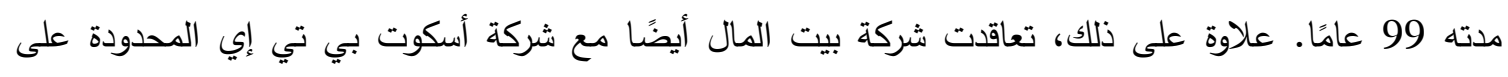
مشاركة الأرباح في أعمال الشركة. ستحصل شركة Warees Investments Pte Ltd على عائد استثماري اسمي ورسوم مهنية مقابل

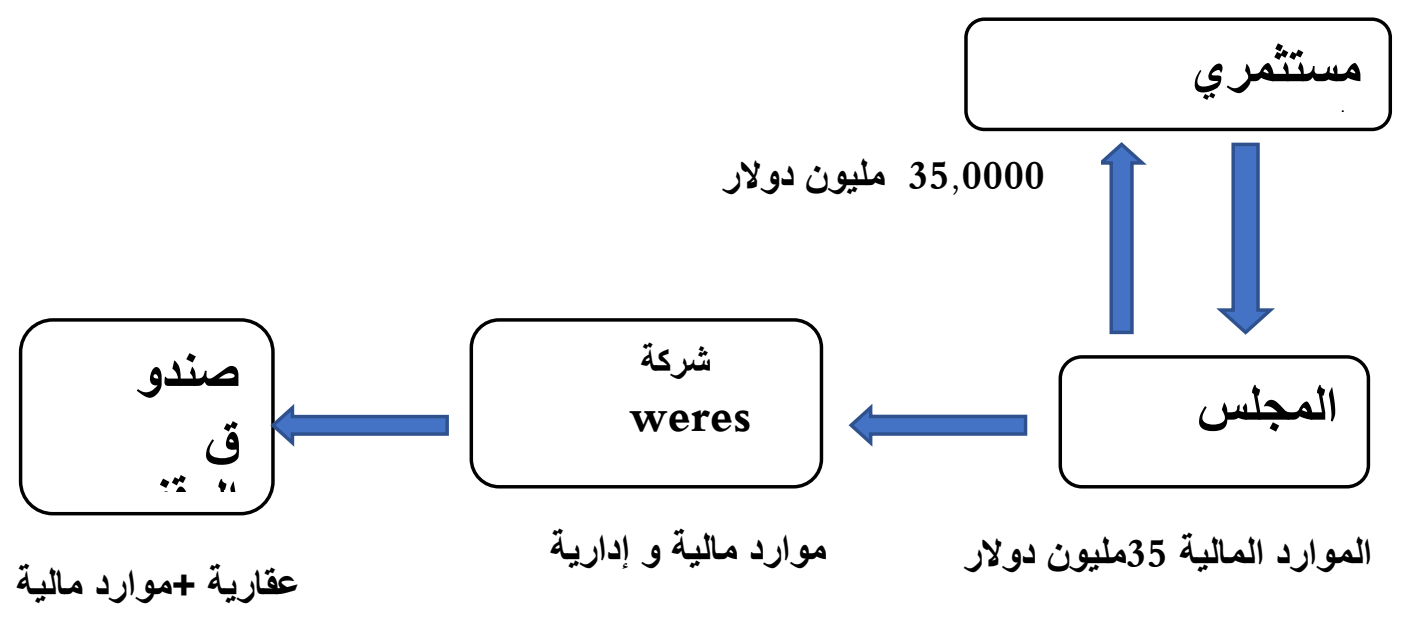

الثكل 2 : ترتيب صكوك المشاركة

6 أسكوت الدولية بي تي إي المحدودة التي تنتمي إلى كابيتال لاند هي شركة إدارة الخدمات التي تدير العديد من الشقق الخدمية في سنغافورة وكذلك في الخارج. 
توزيع العائدات من هذه الصفقة على الثركاء في المشاريع المشتركة كما في الثكل التالي:
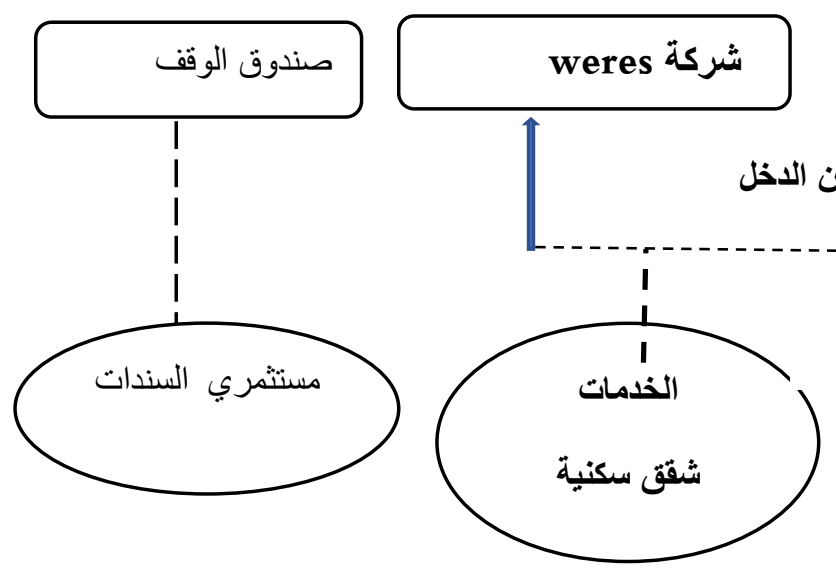

تقسيم الريح من الاخل

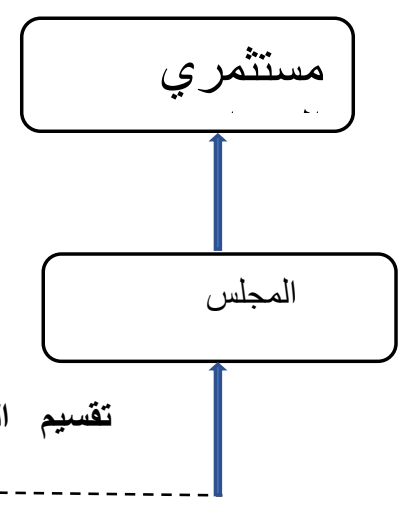

$$
\text { الثكل } 3 \text { : توزبع الربح بين الثركاء }
$$

هذا الحل المبتكر في التمويل من خلال سوق رأس المال زادت قيمة أصول الوقف في شارع بينكولين وله عدة مزايا وضحنها

ب - مشروع طريق الشاطئ 11، وتمويله (Beach Road 11)

تقع بعض أصول الوقف في سنغافورة في مواقع مختلفة، بعضها في أماكن ذات مستوى إيجار منخفض، في حين

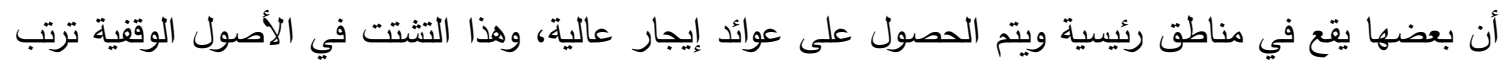
عليه عدة مشاكل في الإدارة والإشراف والصيانة مما ترتب عليه زيادة في التكاليف، والذي انعكس سلبًا على العائد من وراء هذه الأصول(Nagaoka, 2016)، وبناءً على ذلك قرر المجلس الإسلامي المضي قدما في عملية ترحيل الأصول من الأصول ذات العوائد المنخفضة إلى العقارات ذات العائد الأعلى، أستلزم ذلك تجميع كل تلك الأصول فيلكي

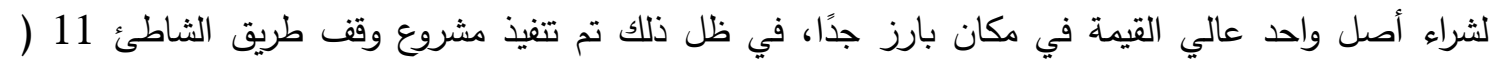
(Beach Road 11 Waqf من أنحاء البلاد ودمجها في مبنى جديد في وسط المدينة بجوار فندق رافليز • (Abdu Karim, 2010)

\section{تمويل المشروع}

نتطرق هنا إلى كيفية تمويل هذا المشروع، وملخص هذا المشروع هو التخلص من الأصول الوقفية ذات العائد

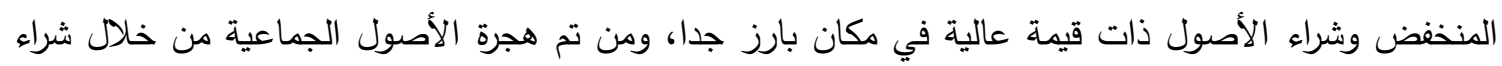

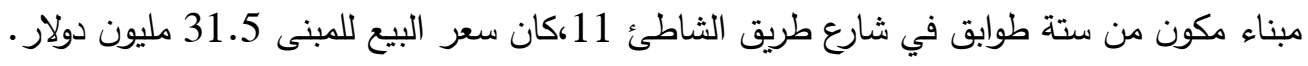


المرحلة الأولى تمثلت في مشروع مشترك بين المجلس MUIS والمستثمرين في صكوك المشاركة لشراء وتجديد عقار تجاري مكون من 6 طوابق بجوار فندق (Raffles) بلغت كلفة المشروع 34 مليون دولار سنغافوري،

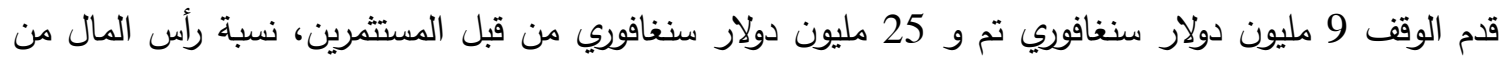
26.5 \% قدمها الوقف إلى 73.5 ٪ جمعت من المستثرين من خلال الصكوك، والتي كانت أيضا نسبة تقاسم

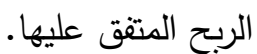

المرحلة الثانية من المشروع وهو مرحلة التأجير ، حيث قامت شركة خاصة SPV1 بتأجير العقار وهي

شركة تابعة مملوكة بالكامل لبيت المال، والثركة SPV2 ستقوم بإدارة الأصول وتضمن إعادة أموال المستثمرين.

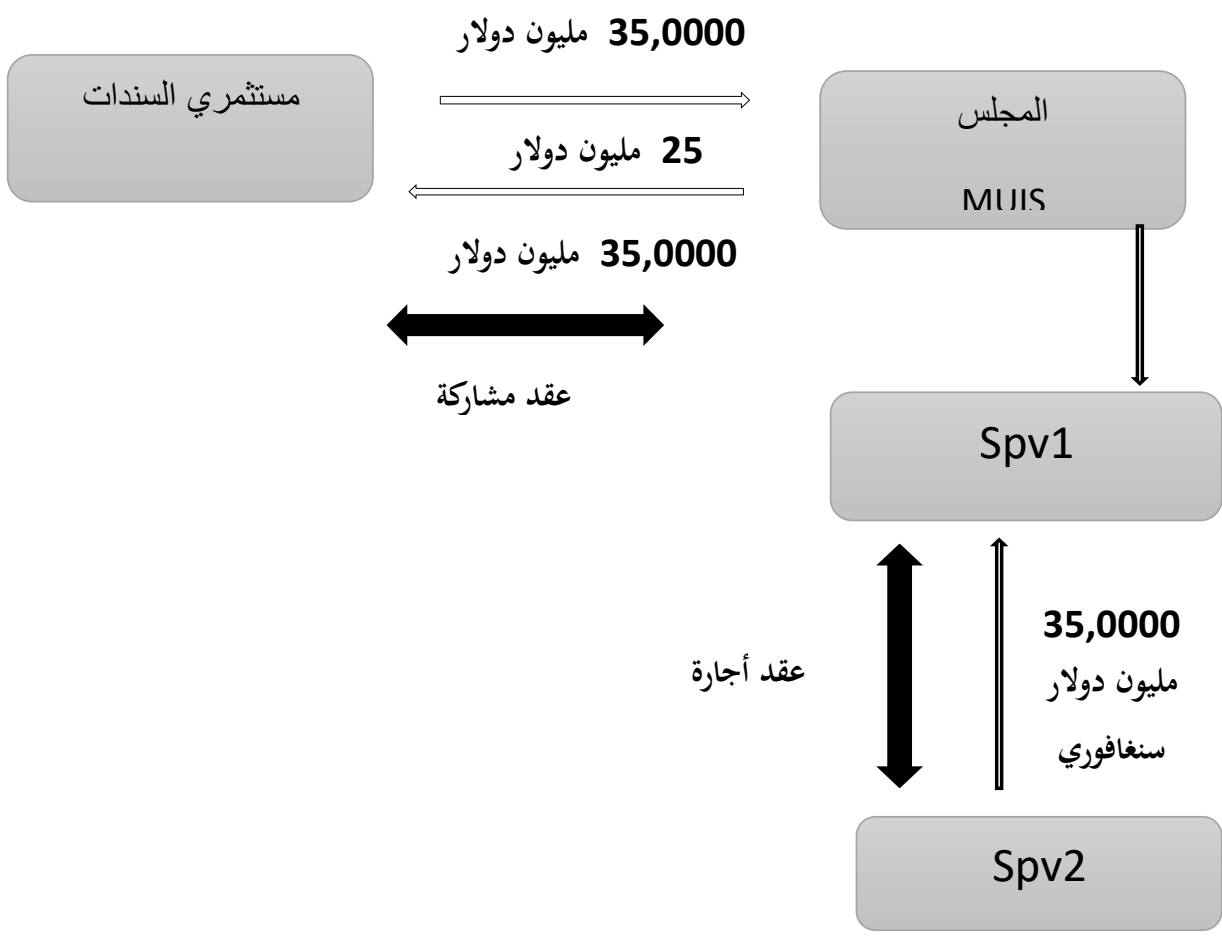

الشكل 4 : تمويل مشروع طريق الشاطئ 11(BEACH ROAD11)

ثالثًاً- استخدام التمويل الداخلي التمويل الداخلي يتمثل في قرض من بيت مال (قرض حسن )، أو استبدال، أو باستخدام أموال الوقف الخاصة.

$$
\text { أ - التمويل من خلال بيت المال }
$$

بيت المال هو صندوق هبات عام يديره المجلس الإسلامي، تم إعداد الصندوق كصندوق الأغراض العامة للجالية

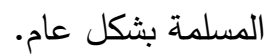

يتم توفير تمويل بدون فوائد في إطار صندوق بيت المال الأوقاف المالية وتطوير المشروع. ينطبق هذا

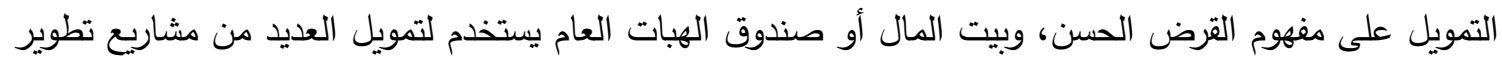

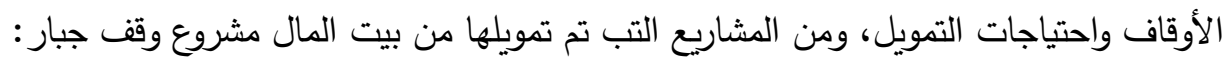
وقف جبار (Waqf Jabbar) في عام 1990م، بدأت إعلادة تطوير المباني الوقفية القديمة بتمويل داخلي من بيت المال لتأخذ نهج الأوقاف الحديثة. 
العقار: هو وقف جبار (waqf Jabbar)، والذي أسس عام 1947م، وكان تحت وصاية المجلس والذي كان عبارة عن أرض شاغرة في طريق دوكو (Duku Roadm) والمستقيدون من هذا الوقف المسجد وأيتام المسلمين، وكانت عملية التطوير إنثاء مسجد بالإضافة إلى وحدات سكنية. تمت عملية التمويل من خلال التمويل المشترك، بين الوقف وبيت المال، حيث يوفر الوقف الأرض وديه ويوفر بيت المال الأموال. وبعد عملية التطوير زادت الإيرادات من الإيجار من 68 دولار سنغافوري سنويًا في عام 1990م إلى حوالي

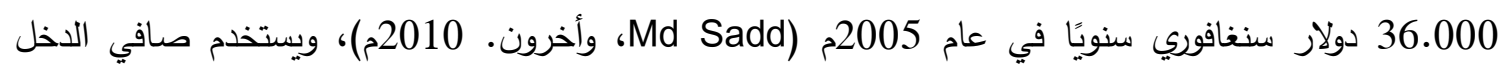
السنوي من الممتلكات لدفع ثمن صالح المسجد (رواتب الأئمة والترميم في المسجد، فواتير الكهرباء) والثق الثاني

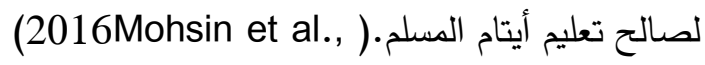
د - الوقف النقدي لمساهمات بناء المساجد شكل أخر من أشكال الوقف، الذي يمارس في سنغافورة منذ 1970م هو الوقف النقدي. هذا الصندوق، المعروف

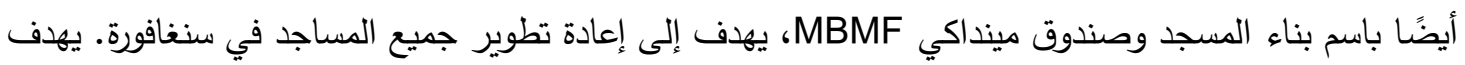
هذا النمط من التمويل إلى إشراك جميع الموظفين المسلمين في المساهمة في تطوير جميع المساجد في سنغافورة من خلال نظام فحص تلقائي يستند إلى إجمالي الدخل الثهري. سيتم بعد ذلك توجيه المبلغ المخصوم من رواتبهم

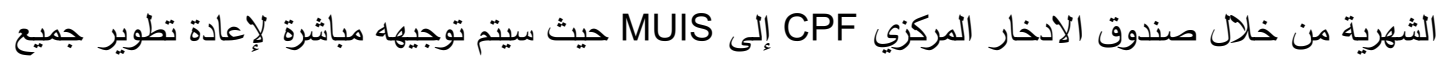
المساجد في سنغافورة، وهذا النوع من الأوقاف النقدية أداة مالية قوية، والتي ستمكن جميع المساجد من الحصول على دخل مستمر لصيانتها ودعمها .(Abdu, 2010; Alareeni, 2018; Alqallaf and Alareeni)

المطلب الرابع: الوقف النقدي في سنغافورة يمارس وقف النقود الأن على نطاق واسع في كثير من البلدان والمجتمعات الإسلامية، وتم إنثاء العديد من الأوقاف النقدية مختلفة الأغراض، هناك صناديق الوقف للمساجد، صناديق المعاقين، تحفيظ القرآن، وكذلك التعليم والبحث العلمي والابتكار وغيرها، واكتسب الوقف النقدي شعبية على خلاف أوقاف الأصول غير المنقولة.

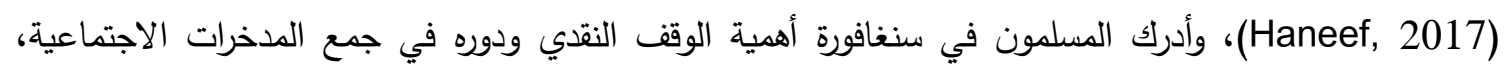
وتحويلها إلى راس مال اجتماعي، وتطوير سوق رأس المال الاجتماعي؛ لتحفيز الدمج بين الأمان الاجتماعي الأي

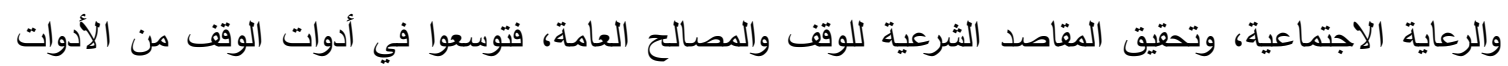

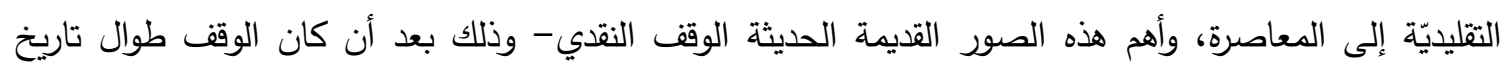

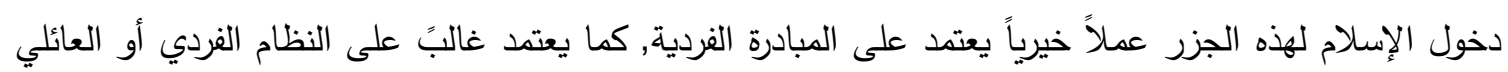

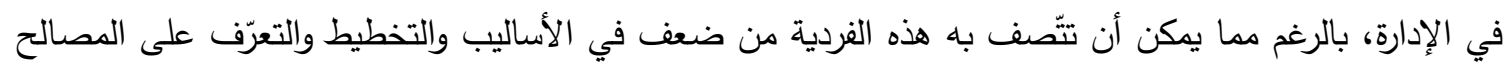
الأكثر أهية، حيث طبق في سنغافورة الوقف النقدي في شكل صناديق وقفية لتمويل احتياجات المجتمع الدينية والتعليمية والصورة الأخرى وهي الصكوك لتمويل مشاريع الوقف الاستثمارية. يتتاول هذا المطلب صور تطبيق الوقف النقدي في سنغافورة وهي كالتالي:

$$
\begin{aligned}
& \text { أولاً: صندوق بناء المساجد } \\
& \text { ثانياً: صندوق وقف علم }
\end{aligned}
$$


ثالثاً: صكوك المشاركة

أولاً - صندوق بناء المساجد (MBF)

1 - تأسيس الصندوق 1

تأسس صندوق بناء المساجد (MBF) في عام 1975م كوسيلة لجمع الأموال لبناء المساجد، حيث كان الغرض (MB

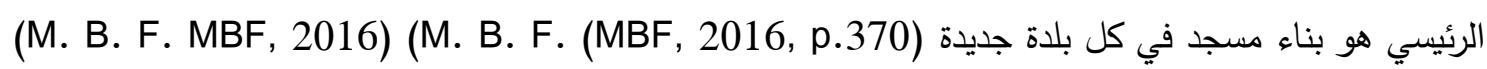

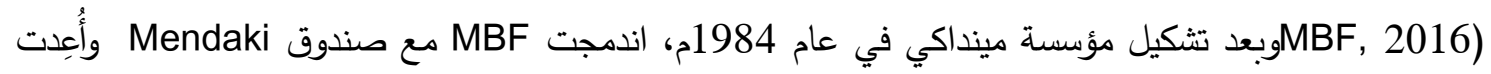

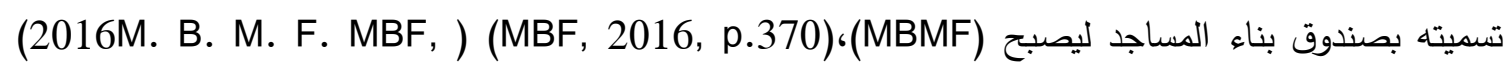
ليصبح أسمه صندوق بناء المسجد منداكي (2016M. B. M. F. MBF, ) ومكون منداكي، يتم استخدام مكون مبنى المسجد لبناء مساجد جديدة بينما يتم استخدام مكون مينداكي لتطوير البرامج التعليمية الاجتماعية لتعزيز العائلات الملايوية المسلمة ورفعها مستواها، ويساهم المسلمون طواعية في هذاه لئاه

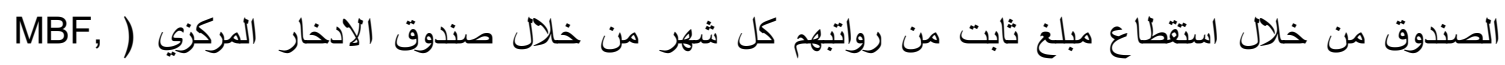
2002)، وكانت المساهمة في هذا الصندوق لا تقتصر على السكان المحليين بل حتى العمال الأجانب والمقيمين الدائمين يكنهم المساهمة في هذا الصندوق المتمعي، وكانت طريقة فعالة لجمع أموال المجتمع من العمال

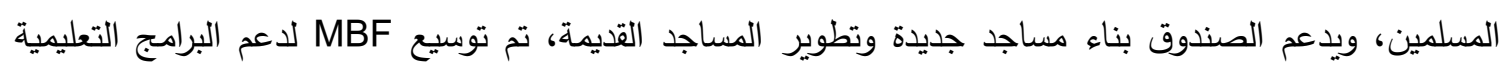
الاجتماعية ومبادرات التعليم الديني، ومع التوسع في عدد السكان المسلمين، إلى جانب التكاليف المتصاعدة للتعليم

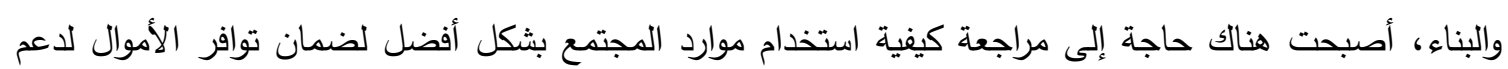

الاحتياجات الاجتماعية والدينية المتتامية داخل المجتمع السنغافوري.

مجلس تنمية مجتمع الملايو المسلمين في سنغافورة: M. B. M. F. MBF) Mendaki): هي مجموعة مساعدة ذاتية رائدة تثكلت عام 1982 مكرسة لتمكين المجتمع الملايو المسلم من خلال التميز في التعليم. وتستهدف برامج MENDAKI إلى حد كبير 30\% من سكان الملايو المسلمين وبالتالي معظم برامجها وقائية

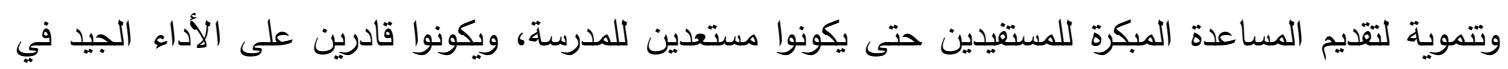
المدرسة وكذلك إعدادهم للمستقبل، وتعمل MENDAKI على نطاق واسع مع الشركاء الذين يثاركون ويدعمون رؤيته ورسالته. وتتألف من الوكالات الحكومية، والمدارس والمساجد، والمنظمات الإسلامية وأرباب العمل والمراكز

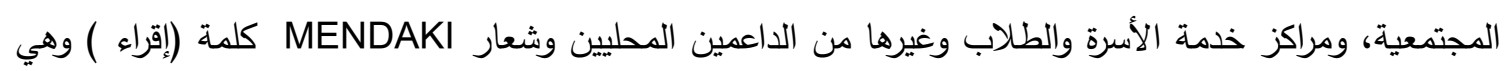
الكلمة الأولى التي أنزلها الله سبحانه وتعالى للنبي محمد للسعي وراء المعرفة. 8

2 - الخلفية التاريخية للصندوق

في أوائل السبعينيات، وجد بعض المسلمين الذين كانوا يعاد توطينهم من قراهم إلى مساكن مجلس التتمية والإسكان

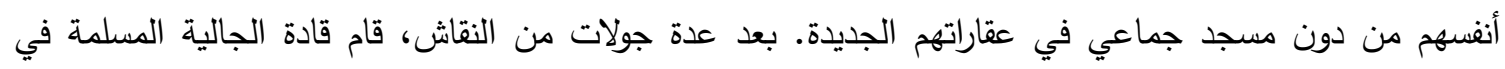

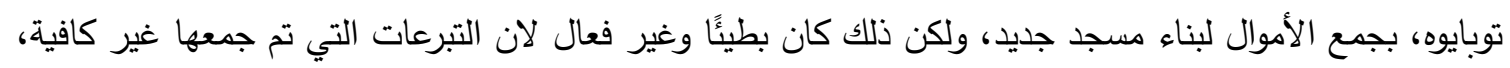

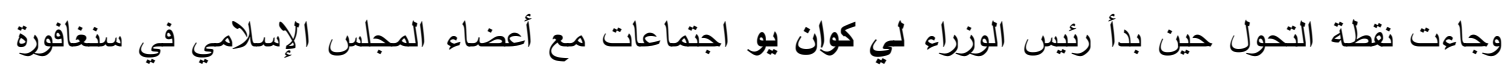
MUIS، وأعضاء البرلمان الماليزي وبعض الوزراء، ومن خلاء هذه الاجتماعات ولدت فكرة صندوق يمكن اعن اعناء

- https://www.3ecpa.com.sg/blog/what-is-mosque-building-and-mendaki-fund-mbmf/ ${ }^{7}$

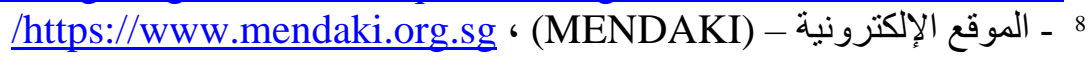


M. )(2016M. B. M. F. MBF, ).7 CPF للمسلمين المساهمة فيه طواعية لبناء المساجد وصيانتها من خلال (M. B. M. F. MBF, 2016)(2016B. M. F. MBF, وبدأ صندوق MBF في جمع التبرعات من خلال CPF في مايو 1975م. بعد أقل من عامين، في أبريل 1977م،

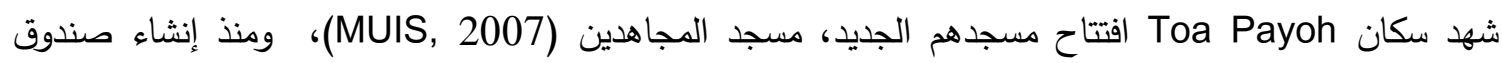
في عام 1975م، تم إكمال 24 مسجداً، وتم إنفاق 297 مليون دولار سنغافوري على بناء وترقية المساجد

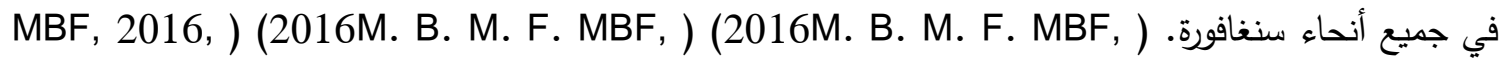

ويتولى المجلس الإسلامي MUIS من خلال تنظيم مسابقات تصميم مساجد جديدة تقدم خلالها مجموعة من الثركات المعمارية عروضها المختلفة ويختار المجلس أفضل التصاميم المناسبة له، وتتولي إدارة المساجد القديمة والمعينة من قبل MUIS صيانة وتطوير المساجد القديمة (MBF, 2002)

3 - معدلات المساهمة في الصندوق في البداية كان الحد الأدنى للمساهمة الثهرية 0,50 دولار للثخص الواحد، بغض النظر عن مقدار الراتب تم

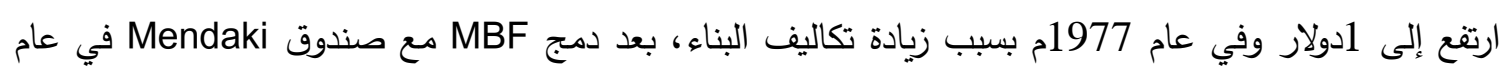

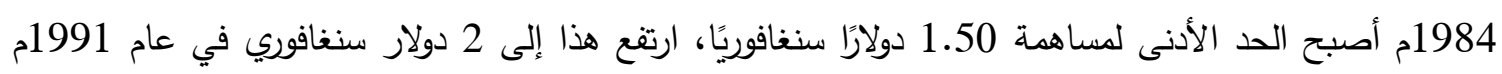

$$
\text { بسبب زيادة في عنصر Mendaki في الصندوق. }
$$
وفي في يوليو 2005 ومارس 2009م تم تقديم معدلات مساهمة أعلى تتراوح بين 3 دولارات سنغافورية و5 دولارات

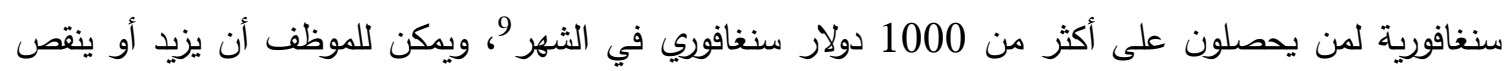

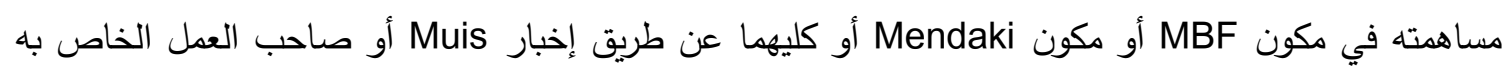
في نموذج محدد، يجوز للموظف كما يمكن له الانسحاب من مكون MBF أو مكون Mendaki أو كليهما إذا رغب في ذلك . (MENDAKI 2019)

وتم التوسيع في استخدام أموال الصندوق ليشمل رفع مستوى المساجد القديمة، وتعزيز التعليم في المدارس الإسلامية من خلال تحسين المناهج، وخدمات تكنولوجيا المعلومات وتدريب المعلمين، ومع هذا التوسع في في فئسي

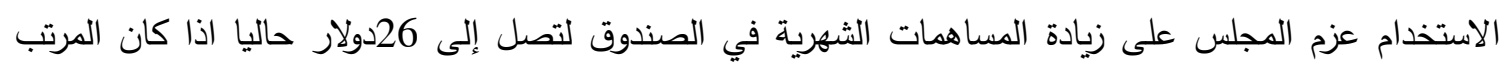
10000 فما فوق. 10 في عام 2015م جمعت MBMF ما يقرب من 24 مليون دولار سنغافوري بهذه الوسائل .(Othman., 2016)

4 في 2008م، تم تعديل قانون الخاص بالصندوق لتوسيع استخدام MBMF ليشمل رفع مستوى المساجد القديمة،

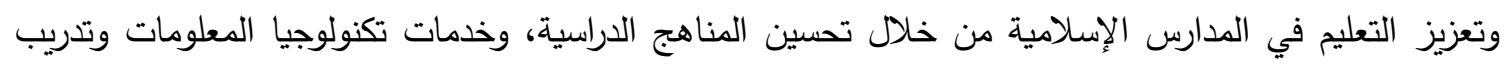
المعلمين. (Hussain, 2016) http://www.mbmf.sg/Employers. Html ${ }^{10}$ 
وساهمت الزيادة في المساهمات الثهرية المقدمة إلى الصندوق (MBMF) ما بين 0.50 دولار سنغافوري و5 دولار سنغافوري في تجميع مبلغ إضافي قدره 3 ملايين دولار سنغافوري في السنة، والذي بدأ سريانها في 2009م (MBF, 2002)، كان هذا القرار لزيادة معدلات المساهمة مثيرا للجدل، ويرجع ذلك إلى حد كبير إلى دلى

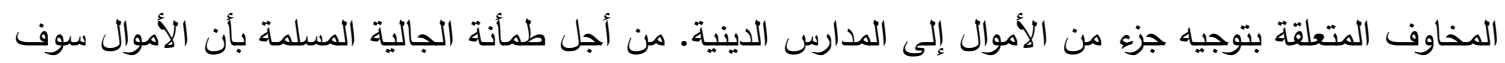

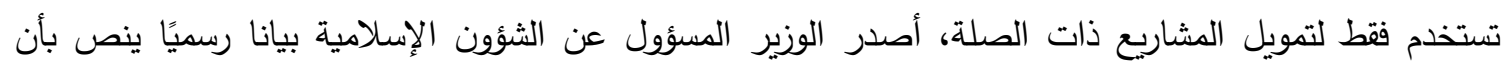

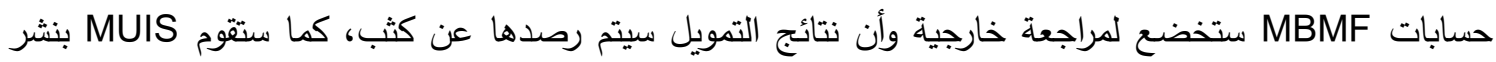
البيانات المالية لنظام المدارس المشتركة في نهاية كل سنة مالية، بالإضافة إلى نشر تكاليف الأرض والبناء لكل

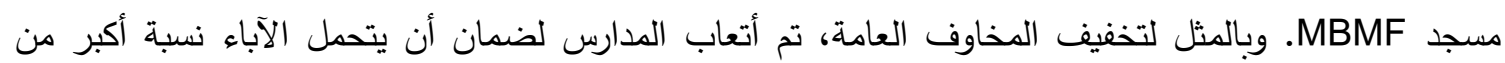
تكلفة تحديد نظام التعليم في الددارس. (Hussain, 2016). 1 - المساجد التي أنثائها الصندوق

جدول 1 : المساجد التي تم انشائها من قبل صندوق بناء المساجد الأسعار بالدولار السنغافوري السي

\begin{tabular}{|c|c|c|c|}
\hline تكلفة بناء المسجد & سنة الانتهاء من البناء & أسم المسجد & ت \\
\hline 6 مليون & 2016م & مسجد الفلاح & 1 \\
\hline 3.65مليون & 2016م & مسجد سلطان & 2 \\
\hline 15.9 مليون & 2015م & مسجد الأنصار & 3 \\
\hline 16.5 مليون & 2015م & مسجد الإصلاح & 4 \\
\hline ا 1.2 مليون & 2015 & مسجد النعيم & 5 \\
\hline 0.7 مليون & 2015 & مسجد دار الأمان & 6 \\
\hline ا 1.1 مليون & 2015 & مسجد الهذى & 7 \\
\hline ا 1.1 مليون & 2015 & مسجد حاج محمد صالح & 8 \\
\hline ( ) 0.9 مليون & 2015 & مسجد حاجي يوسف & 9 \\
\hline (1.3 مليون & 2015 & مسجد مولانا محمد علي & 10 \\
\hline ا 1.1 مليون & 2014 & الأمين & 11 \\
\hline ا 1.2 مليون & 2014 م & الاستقامة & 12 \\
\hline ا 3.1 مليون & 2014 م & الكاف أبر سيرانجون & 13 \\
\hline 2 2.8 مليون & 2014 & جمعية الربيعة & 14 \\
\hline 3.7 & م 2014 & المجاهدين & 15 \\
\hline ( & 2013 & مسجد النور & 16 \\
\hline 10.5 مليون & 2009 & مسجد المودة & 17 \\
\hline 9.0 مليون & 2006 & النهضة & 18 \\
\hline 5.3 & 2004 & الإيمان & 19 \\
\hline ا 8.8 مليون & 2004 & Assyafaah & 20 \\
\hline 1.02 مليون & 2002 & Assyakirin & 21 \\
\hline ( & م 2000 & الإستصناف & 22 \\
\hline ( 4.7 مليون & 1994م & الكاف كغ ميلايو & 23 \\
\hline 8 ( 8.0 مليون & 1993 م & Raudhah سوراو & 24 \\
\hline
\end{tabular}




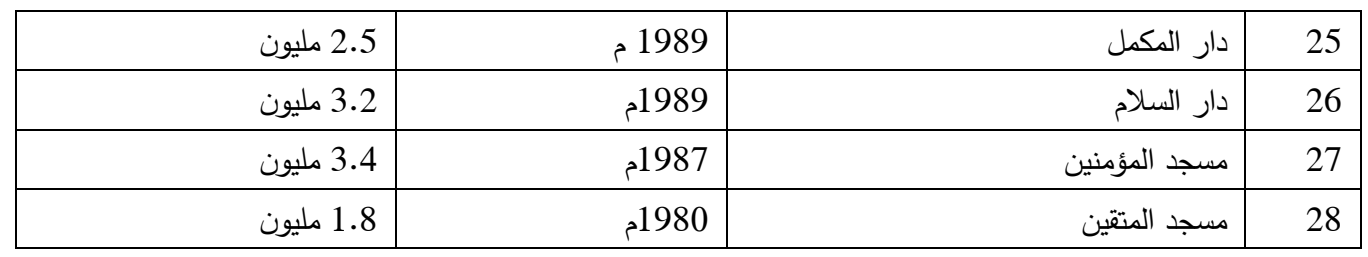

ثانياً: صندوق وقف علم (IImu)

تم إطلاق هذا الصندوق الوقفي في عام 2012م، وتعني كلمة "IImu" "علم " المعرفة باللغتين العربية والماليزية، ويتماشى مع هدف هذا الصندوق الوقفي الذي يهدف إلى تمويل التعليم الإسلامي في سنغافورة خصوصًا المدارس بدوام كامل أو جزئي.

وإنشاء هذا الصندوق على غرار صندوق المساجد، حيث تثكل المدارس الإسلامية مؤسسة مهمة في خلق القادة الدينيين في المجتمع الإسلامي السنغافوري، ويوفر التعليم الإسلامي في المدارس الدينية الأسس التعليمة

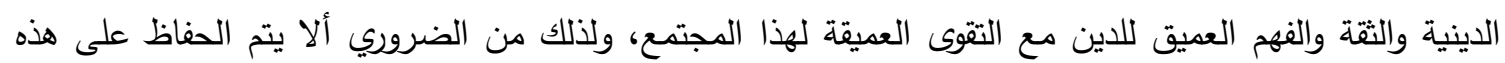
المؤسسة فحسب، بل العمل على تطويرها مستقبلاً وازدهارها (Haneef, 2017)

$$
1 \text { - لماذا صندوق علم في شكل وقف؟ }
$$

من تقاليد المجتمع الملايو أستخدم العديد من مبادرات جمع الأموال في شكل صدئ صدقات التي تلبي الاحتياجات الفورية

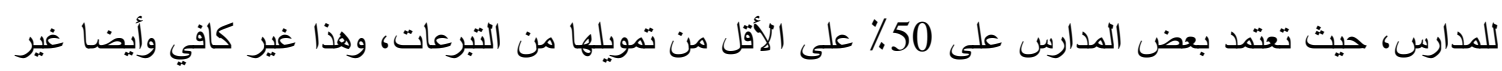
مستدام. لإنشاء مؤسسة تعليمية مستدامة تحتاج إلى تدفق ثابت للاخل للبقاء على المدى الطويل، لذلك فإن مثل

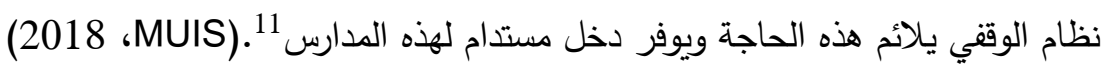

2 يبين الثكل البياني التالي طريقة عمل وقف علف علم:

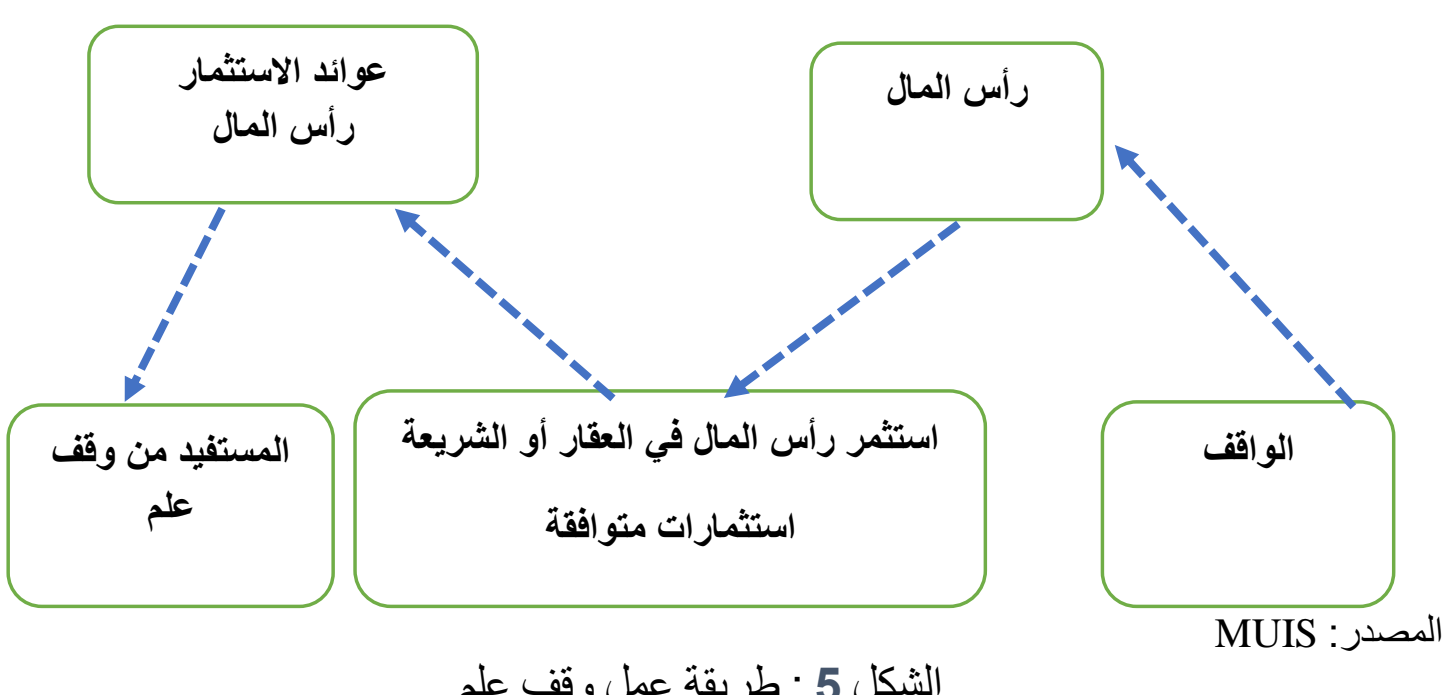

الثكل 5 : طربقة عمل وقف علم

https://www.muis.gov.sg/wakaf/Creating-My-Wakaf/Wakaf-Ilmu-for-Education ${ }^{11}$ 
الواقف: الثخص الذي أوقف المال و المساهمة في الوقف ومناح للجميع، وهذا يتيح مشاركة واسعة للمجتمع، وكذللك فرصة لتوسيع دور الوقف في سنغافورة، كونه وقفقًا نقديًا. رأس المال: وهو رأس المال الموقوف وسيتم استثماره في العقارات أو في الصناديق المتوافقة مع الشريعة الإسلامية. عوائد الاستثمار : صافي الدخل المراد صرفه سنوياً للمستفيدين. المستفيدون: مدارس التعليم الإسلامي (مدارس بدوام كامل وبدوام جزئي). ويستطيع من يرغب في المساهمة في وقف علم بكل يسر أن يتبرع لصندوق دعم التعليم الديني من خلال موقع على الأنترنيت بخطوات بسيطة وهي 1- تختار الخدمة، 2- تحدد القيمة التي ترغب بالمساهمة، 3 - تدخل

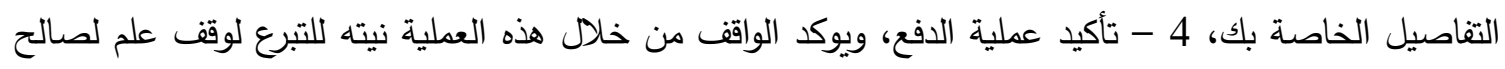
المستفيدين، وكذلك يؤكل المجلس الإسلامي بمهمة توزيع العائد على المستقيدين. 12 أولا : النتائج : 1- تجربة سنغافورة تجربة رائدة في تتمية وتطوير الأوقاف، حيث نجحت في تحويل الأصول الوقفية إلى أوقاف

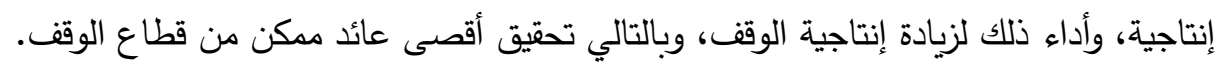
2- أستند المجلس MUIS في إدارة وتطوير الأوقاف على سلطة القانون، بموجب قانون(AMLA) ، الذي نظم عمل المجلس ومنحه الصلاحية في التصرف في الأوقاف حسب ما تقتضيه مصلحة الوقف والمستفيدين، وبما

$$
\text { يتقق مع الثريعة، ولاسيما في جانب الاستثمار . }
$$

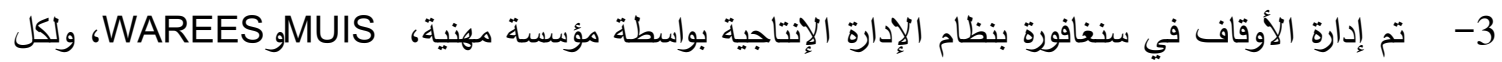

$$
\text { منهما دور ومهام محددة بوضوح، ولديها خبرة في أدوارها ومسؤولياتها. }
$$

4- نجح المجلس MUIS و WAREES بأسلوب مهني وريادي في استخدام الطرق التقليدية، وكذلك استخدام

$$
\text { الأساليب الحديثة في تطوير وتتمية الأوقاف. }
$$

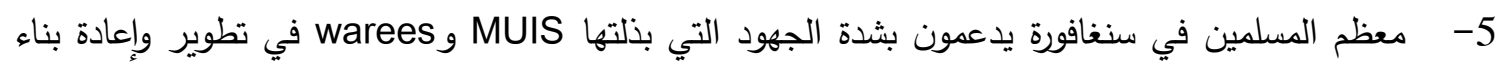

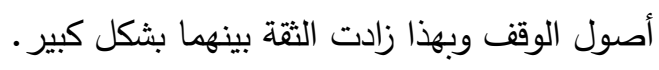

المراجع

السيد, طايل مصطفى كمال (1999م). القرار الاستثماري في البنوك الإسلامية.

قحف, منذر (1997م). تمويل وتتمية أموال الأوقاف- تطوير الأوقاف الإسلامية وتتميتها نواكثط- موريتانيا.

\section{References}

Alareeni, B. (2018). Does corporate governance influence earnings management in listed companies in Bahrain Bourse?, Journal of Asia Business Studies, 12(4), 551-570. https://doi.org/10.1108/JABS-06-2017-0082

Alareeni, B. (2018). The impact of firm-specific characteristics on earnings management: evidence from GCC countries. International Journal of Managerial and Financial Accounting, 10(2), 85-104. https://doi.org/10.1504/IJMFA.2018.091659 
Alqallaf, H. and Alareeni, B. (2018). Evolving of Selected Integrated Reporting Capitals among Listed Bahraini Banks, International Journal of Business Ethics and Governance, 1(1), 15-36. https://doi.org/10.51325/ijbeg.v1i1.10

Al-Sayed, Tayel Mustafa Kemal (1999). The investment decision in Islamic banks (in Arabic).

Arifn, J., \& Kudus, S. (2015). Pengembangan harta wakaf di singapura .Jurnal ekonomi syariah- universitas indraprasta pgri jakarta, pp. 25.

Green, A., \& Razak, R. A. (2007). Continuing the Legacy: 30 Years of the Mosque Building Fund in Singapore. Majlis Ugama Islam Singapura.

Hamber, N., \& Haneef, M. (2017). Waqf-based social micro venture fund: A proposal for the Malay-muslim community in Singapore. Journal of King Abdulaziz University: Islamic Economics, 30(1). https://doi.org/10.4197/Islec.30-1.3

Hussain, Z. (2016). Changes to muslim fund passed. The straits times.

Ibrahim, A., \& Datuk, T. S. (1965). The legal status of the Muslims in Singapore. Malayan Law Journal.

Kamsani, F. R. (2005). Islamic Real Estate Finance and Middle East Opportunities. In REDAS Conference 'Construction and Property Prospects 2005'Orchard Hotel, Singapore.

Karim, S. B. A. (2010). Contemporary shari'a compliance structuring for the development and management of waqf assets in Singapore. Kyoto Bulletin of Islamic Area Studies, 3(2), 143-164.

Khan, f. A., \& siddiqui, d. A. (2018). Islamic (sukuk) vs. Conventional financing: analysis of profitability. International Journal of Experiential Learning \& Case Studies, 3(2), 257-246. https://doi.org/10.22555/ijelcs.v3i2.2490

Khouildi, M. Y., \& Kassim, S. H. (2018). An Innovative Financing Instrument To Promote The Development Of Islamic Microfinance Through Socially Responsible Investment Sukuk. Journal of Islamic Monetary Economics and Finance, 4(2), 237-250. https://doi.org/10.21098/jimf.v4i2.935

Mbf, m. B. F. (2002) .Postimperial and postcolonial literature in English.

Mbf, m. B. F. (2016). Postimperial and postcolonial literature in English.

Mohsin, M. I. A., Dafterdar, H., Cizakca, M., Alhabshi, S. O., Razak, S. H. A., Sadr, S. K., \& Obaidullah, M. (2016). Financing the development of old Waqf properties. New York: Palgrave Macmillan. https://doi.org/10.1057/978-1-137-58128-0

Qahf, Munther (1997). Financing and developing Awqaf funds - developing Islamic Awqaf, Nouakchott, Mauritania. (in Arabic) 